\title{
Rhizobium Population Genetics: Genetic Variation Within and Between Populations from Diverse Locations
}

\author{
By S. P. HARRISON, ${ }^{1,2} \uparrow$ D. G. JONES ${ }^{1 *}$ and J. P. W. YOUNG ${ }^{2}$ \\ ${ }^{1}$ Department of Agricultural Botany, University College of Wales, Aberystwyth SY23 3DD, UK \\ ${ }^{2}$ John Innes Institute, Norwich NR4 $7 U H, U K$
}

(Received 22 September 1988; revised 2 January 1989; accepted 30 January 1989)

Polyacrylamide gel electrophoresis (PAGE) of isoenzymes of chromosomal origin, and plasmid profile analyses, were used to investigate genetic variation within and between natural populations of Rhizobium leguminosarum biovar trifolii from diverse sources. PAGE showed that, within the biovar in general, relatively few alleles existed for the enzyme loci studied. There was a strong genetic disequilibrium between loci, suggesting that chromosomal recombination is rare. Both PAGE and plasmid profile analysis revealed differences in the degree of strain polymorphism at the sites examined. At sites which were acidic, improved (by liming) and neutral, strain variation was found to be low, intermediate and high, respectively.

\section{INTRODUCTION}

The baiting of soil samples with a single white clover (Trifolium repens) cultivar under growthroom conditions to obtain indigenous Rhizobium leguminosarum biovar trifolii has been shown to provide samples of rhizobia unbiased in respect of the strains identified by enzyme polymorphism and plasmid profile (Harrison et al., 1987; and our unpublished results). Not only can an examination of enzyme polymorphism using polyacrylamide gel electrophoresis (PAGE), be used to give an indication of the degree of chromosomal uniformity within a collection of Rhizobium (Young, 1985) but it can also be used to describe degrees of strain heterogeneity in natural populations. Plasmid profile analysis, through agarose gel electrophoresis, is also particularly useful in the investigation of the latter (Glynn et al., 1985; Bromfield et al., 1987).

These techniques have proved to be very useful in an examination of these aspects in Escherichia coli populations. Restricted chromosomal variation has been demonstrated using enzyme electrophoresis by a number of workers (Milkman, 1975; Selander \& Levin, 1980; Caugant et al., 1981). Caugant et al. (1981) also examined cryptic plasmids which, by contrast, were very variable. The presence of chromosomal linkage disequilibrium was again shown by Whittam et al. (1983) and by Ochman \& Selander (1984), who suggested that populations are clonal and that certain clones recur throughout unrelated populations.

Work by Young (1985) and Young et al. (1987) on single populations suggests that chromosomal variation is also limited in the species $R$. leguminosarum. However, other studies (Noel \& Brill, 1980; Dughri \& Bottomley, 1983a, b, 1984; Bromfield et al., 1986; Thurman \& Bromfield, 1988) have indicated the existence of heterogeneous groups of strains within natural populations. The degree of heterogeneity demonstrated clearly relies heavily on the identification method employed, and a group of isolates homogeneous for one characteristic may vary in respect of another (Noel \& Brill, 1980; Dughri \& Bottomley, 1983a).

\footnotetext{
† Present address: Welsh Plant Breeding Station, Plas Gogerddan, Aberystwyth SY23 3EB, UK.
}

Abbreviations: BGAL, $\beta$-galactosidase; ET, electrophoretic type; G6PD, glucose-6-phosphate dehydrogenase; SOD, superoxide dismutase. 
As the results of such work have depended on the method used, the host and other environmental factors, they are not strictly comparable. A widespread comparison of populations of a single biovar from sites of varying geography and ecology, using the same evaluation methods, has not been carried out. Such a study of the genetic variation in indigenous populations of $R$. leguminosarum biovar trifolii would be of both ecological and agronomic interest. Here, an investigation is reported which used PAGE of chromosomal isoenzymes and agarose gel electrophoresis of plasmid DNA to screen isolates from ten geographically and ecologically diverse sites.

\section{METHODS}

Soil sampling and strain isolation. Soil samples were collected from ten geographically and ecologically varying sites (Table 1). Ten samples, taken on a transect at $2 \mathrm{~m}$ intervals, were removed from each location. This was achieved by loosening the top $10 \mathrm{~cm}$ of soil with a sterile trowel followed by the removal of a 'core' in a sterile $30 \mathrm{ml}$ universal bottle (Sterilin). These soils were then used to inoculate seedlings of white clover (Trifolium repens) cv. Nesta grown on Jensen's (1942) nitrogen-free agar slopes at $16^{\circ} \mathrm{C}$ under a $16 \mathrm{~h} \mathrm{light} / 8 \mathrm{~h}$ dark cycle. The seedlings were derived from seeds that had been surface sterilized with $20 \%(\mathrm{v} / \mathrm{v})$ sodium hypochlorite, rinsed thoroughly in sterile distilled water and germinated on water agar.

Inoculum was prepared by mixing $10 \mathrm{~g}$ soil $(1 \mathrm{~g}$ from each sample point on the transect) with $90 \mathrm{ml}$ quarterstrength Jensen's (1942) $\mathrm{N}$-free liquid medium at $4^{\circ} \mathrm{C}$ by agitation on a wrist-action shaker for $1 \mathrm{~h}$ at 250 cycles $\mathrm{min}^{-1}$. In addition, at locations where within-site variation was considered (Table 2), four of these samples from alternate sampling points ( $4 \mathrm{~m}$ intervals) were chosen for sub-site analysis. In this case $10 \mathrm{~g}$ soil from each sample was treated as above.

From both parent and sub-site soil suspensions the resulting $10^{-1}$ dilutions were diluted by a further factor of ten and $1 \mathrm{ml}$ aliquots of these suspensions were used to inoculate single plants (one hundred per soil sample). The $\mathrm{pH}$ of each soil was also determined by measuring the $\mathrm{pH}$ of $10 \mathrm{~g}$ soil shaken in $90 \mathrm{ml}$ sterile deionized water as above (mean of three readings). The populations of Rhizobium were estimated by Brockwell's most probable number plant infection method (Brockwell, 1963; Vincent, 1970).

After 6 weeks, one nodule was removed at random from each plant, crushed in a microtitre plate (Sterilin) and streaked out on TY agar plates (Beringer, 1974). Each strain was subcultured to ensure Rhizabium purity. Isolates were tested for nodulation of clover cv. Nesta to authenticate them as Rhizobium; all were positive.

Enzyme electrophoresis. All isolates were examined by PAGE of three enzymes (Young, 1985; Harrison et al., 1987): glucose-6-phosphate dehydrogenase (G6PD), superoxide dismutase (SOD) and $\beta$-galactosidase (BGAL). The alleles of each locus were labelled alphabetically with a single letter in order of descending PAGE mobility. Each combination of variants for a particular strain for the three single enzyme bands was treated as a distinct genetic class or electrophoretic type (ET) (Caugant et al., 1981).

Analysis of plasmid profiles. Random samples of 40 and 30 isolates from each major site and sub-site, respectively, were examined by agarose gel electrophoresis for variation in plasmid size and distribution. Strains were grown in PA medium (Hirsch et al., 1980) overnight (to a concentration of approximately $10^{7}$ cells ml $^{-1}$ ) following inoculation with actively growing culture. Rhizobial cell lysis and the electrophoretic method were by slight modification of the method of Eckhardt (1978) described by P. R. Hirsch (personal communication). One ml of cell culture was centrifuged and to the pellet was added $50 \mu \mathrm{l}$ of lysis mix $\left(1 \mathrm{mg}\right.$ lysozyme $\mathrm{ml}^{-1}$ and 1 unit RNAase $\mathrm{ml}^{-1}$ in $25 \%(\mathrm{w} / \mathrm{v})$ sucrose, $0.025 \mathrm{M}$-Tris/HCl). This mixture was immediately transferred to the sample wells of a $0.65 \%(\mathrm{w} / \mathrm{v})$ agarose gel. Behind the wells was incorporated a single wide well containing $0.4 \%(\mathrm{w} / \mathrm{v})$ agarose $/ 1 \%(\mathrm{w} / \mathrm{v})$ SDS. A BRL horizontal gel kit was used to run gels at $150 \mathrm{~V}$ for $4 \mathrm{~h}$ in Tris/borate buffer $(\mathrm{pH} 8 \cdot 3)$. Gels were stained in a solution of $1 \mu \mathrm{g}$ ethidium bromide $\mathrm{ml}^{-1}$ for $40 \mathrm{~min}$. Plasmid sizes were estimated by calibration against the relative mobilities of a number of plasmids of known size (Harrison et al., 1988).

Analysis of genetic and genotypic diversity. Analysis of genetic diversity has been employed by Young (1985) and Young et al. (1987) and is based on the gene diversity measure of Nei (1978). The genetic diversity of each locus, $h=1-\sum X_{\mathrm{i}}^{2}$, where $X_{\mathrm{i}}=$ frequency of the $i^{\text {th }}$ allele: frequency $=$ (no. of times an allele occurs)/(total no. of isolates).

Genotypic diversity, $h x$, is also represented by the formula $h x=1-\sum X_{1}^{2}$; but here $X_{\mathrm{i}}$ is the frequency of the $i^{\text {th }} \mathrm{ET}$; its use as a means of indicating variation in bacterial populations has been described by Selander $e t$ al. (1986).

\section{RESULTS AND DISCUSSION}

\section{Implications with regard to general genetic variation within the biovar trifolii}

Limitation of allelic variation is demonstrated through an examination of the data in Table 3 in terms of the total mean genetic diversity of the enzymes G6PD, SOD and BGAL (Table 4a) for isolates from all the sites combined. Mean genetic diversity, $\bar{h}$, is the sum of the genetic 
Table 1. Sites from which isolates were sampled

Site

Tal-y-Bont (T) Dyfed
Bronant 1 (B1) Dyfed

Bronant 2 (B2)

Pwllpeiran ( $\mathrm{Pw})$

Bowstreet (BS) Dyfed

Frongoch (F) Dyfed

Penglais (Pen) Dyfed

Costessey (C) Norfolk

Garveston (G) Norfolk

Blackawton (Bn) Devon
Grid ref. $\quad \mathrm{pH} \quad \begin{aligned} & \text { Approx. no. } \\ & \text { of cells } \mathrm{g}^{-1 *}\end{aligned}$

$\left.\begin{array}{lll}\text { SN 677914 } & 4.3 & 60 \\ \text { SN 626673 } & 4.4 & 60\end{array}\right\}$

SN $635685 \quad 5.9 \quad 2 \times 10^{4}$

SN $773748 \quad 6.1 \quad 2 \times 10^{5}$

SN 617846

SN 605827

SN 595823

TG 184214

TG 018078

SX 805513

$\left.\begin{array}{ll}6 \cdot 2 & 6 \times 10^{4} \\ 6 \cdot 3 & 6 \times 10^{4} \\ 6 \cdot 5 & 6 \times 10^{5} \\ 6 \cdot 7 & 2 \times 10^{7} \\ 6 \cdot 9 & 2 \times 10^{6} \\ 7 \cdot 5 & 6 \times 10^{3}\end{array}\right\}$

Site description

Acidic peaty podsol

Previously acidic peaty podsol, improved through liming ( 3 yrs previously)

Previously acidic mineral soil, improved through liming ( 5 yrs previously)

Neutral mineral soil from permanent pasture containing clover

* Fiducial limits are determined by dividing or multiplying numbers by $6 \cdot 6$.

Table 2. Summary of sub-sites examined

\begin{tabular}{|c|c|c|}
\hline Sub-site & $\mathrm{pH}$ & $\begin{array}{l}\text { Approx. no. } \\
\text { of cells } \mathrm{g}^{-1 *}\end{array}$ \\
\hline $\begin{array}{l}\text { Bronant } 1 / 1(\mathrm{~B} 1 / 1) \\
\text { Bronant } 1 / 2(\mathrm{~B} 1 / 2) \\
\text { Bronant } 1 / 3(\mathrm{~B} 1 / 3) \\
\text { Bronant } 1 / 4(\mathrm{~B} 1 / 4)\end{array}$ & $\begin{array}{l}4 \cdot 4 \\
4 \cdot 2 \\
4 \cdot 2 \\
4 \cdot 5\end{array}$ & $\begin{array}{l}60 \\
60 \\
60 \\
60\end{array}$ \\
\hline $\begin{array}{l}\text { Bronant 2/1 (B2/1) } \\
\text { Bronant } 2 / 2(\mathrm{~B} 2 / 2) \\
\text { Bronant } 2 / 3(\mathrm{~B} 2 / 3) \\
\text { Bronant } 2 / 4 \text { (B2/4) }\end{array}$ & $\begin{array}{l}5 \cdot 7 \\
5 \cdot 8 \\
6 \cdot 1 \\
6 \cdot 0\end{array}$ & $\begin{array}{l}6 \times 10^{2} \\
2 \times 10^{3} \\
6 \times 10^{4} \\
2 \times 10^{4}\end{array}$ \\
\hline $\begin{array}{l}\text { Pwllpeiran/1 }(\mathrm{Pw} / 1) \\
\text { Pwllpeiran/2 }(\mathrm{Pw} / 2) \\
\text { Pwllpeiran/3 }(\mathrm{Pw} / 3) \\
\text { Pwllpeiran/4 }(\mathrm{Pw} / 4)\end{array}$ & $\begin{array}{l}6 \cdot 1 \\
6 \cdot 0 \\
6 \cdot 0 \\
5 \cdot 9\end{array}$ & $\begin{array}{l}2 \times 10^{6} \\
2 \times 10^{4} \\
6 \times 10^{4} \\
6 \times 10^{3}\end{array}$ \\
\hline $\begin{array}{l}\text { Garveston/1 (G/1) } \\
\text { Garveston/2 (G/2) } \\
\text { Garveston/3 (G/3) } \\
\text { Garveston/4 (G/4) }\end{array}$ & $\begin{array}{l}6 \cdot 2 \\
6 \cdot 4 \\
5 \cdot 7 \\
7 \cdot 1\end{array}$ & $\begin{array}{l}6 \times 10^{5} \\
2 \times 10^{5} \\
6 \times 10^{6} \\
6 \times 10^{3}\end{array}$ \\
\hline
\end{tabular}

* Fiducial limits are determined by dividing or multiplying numbers by 6.6 .

Table 3. Number of isolates of each ET obtained from particular sites

No. of isolates of ET indicated*:

$\begin{array}{lcrrrrrrrrrrr}\text { Site } & \text { MFK } & \text { MFM } & \text { MFP } & \text { MSK } & \text { MSM } & \text { MSQ } & \text { MSS } & \text { SSM } & \text { SSQ } & \text { SSS } & \text { Others } & \text { Totals } \\ \text { T } & 0 & 44 & 0 & 0 & 6 & 1 & 0 & 0 & 0 & 0 & 0 & 51 \\ \text { B1 } & 0 & 17 & 1 & 0 & 0 & 1 & 0 & 0 & 0 & 0 & 0 & 19 \\ \text { B2 } & 0 & 5 & 0 & 0 & 10 & 27 & 8 & 6 & 30 & 0 & 0 & 86 \\ \text { Pw } & 3 & 6 & 0 & 0 & 8 & 8 & 0 & 17 & 40 & 0 & 8 & 90 \\ \text { BS } & 10 & 15 & 7 & 5 & 8 & 7 & 2 & 0 & 1 & 0 & 0 & 55 \\ \text { F } & 21 & 33 & 0 & 15 & 14 & 0 & 0 & 0 & 0 & 0 & 5 & 88 \\ \text { Pen } & 1 & 48 & 24 & 3 & 6 & 0 & 1 & 0 & 0 & 0 & 0 & 83 \\ \text { C } & 0 & 9 & 0 & 4 & 36 & 0 & 15 & 5 & 7 & 0 & 0 & 76 \\ \text { G } & 0 & 10 & 10 & 5 & 34 & 0 & 19 & 0 & 0 & 0 & 1 & 79 \\ \text { Bn } & 5 & 7 & 5 & 3 & 7 & 0 & 8 & 34 & 3 & 18 & 4 & 94 \\ \text { Totals } & 40 & 194 & 47 & 35 & 129 & 44 & 53 & 62 & 81 & 18 & 18 & 721\end{array}$

* The three letters indicate the electrophoretic mobility class of the enzymes G6PD, SOD and BGAL, respectively. 
Table 4. Genetic and genotypic diversity at each site (a) and sub-site (b)

Mean genetic diversity $\bar{h}=h_{\mathrm{G} 6 \mathrm{PD}}+h_{\mathrm{SOD}}+h_{\mathrm{BGAl}} / 3$, where $h_{\mathrm{G} 6 \mathrm{PD}}, h_{\mathrm{SOD}}$ and $h_{\mathrm{BGAL}}$ are the genetic diversity values for the G6PD, SOD and BGAL loci respectively; 3 is the number of loci examined. Genetic diversity, $h=1-\sum X_{i}^{2}$, where $X_{1}$ is the frequency of the $\imath^{\text {th }}$ allele (frequency $=$ no. of times an allele occurs/total number of isolates). Genotypic diversity, $h x=1-\sum X_{\mathrm{i}}^{2}$, where $X_{\mathrm{i}}$ is the frequency of the $l^{\text {th }}$ ET (frequency $=$ no. of times each ET occurs/no. of isolates). Numbers of alleles and ETs are given in parentheses where appropriate.

\begin{tabular}{|c|c|c|c|c|c|}
\hline & $h_{\mathrm{G} 6 \mathrm{PD}}$ & $h_{\mathrm{SOD}}$ & $h_{\mathrm{BGAL}}$ & $\bar{h}$ & $h x$ \\
\hline \multicolumn{6}{|l|}{ (a) Site } \\
\hline $\mathrm{T}$ & $0 \cdot 00(1)$ & $0.24(2)$ & $0.04(2)$ & $0 \cdot 09$ & $0 \cdot 24(3)$ \\
\hline B1 & $0.00(1)$ & $0 \cdot 10(2)$ & $0 \cdot 20(3)$ & $0 \cdot 10$ & $0.19(3)$ \\
\hline B2 & $0.48(2)$ & $0 \cdot 11(2)$ & $0.49(3)$ & $0 \cdot 36$ & $0.75(6)$ \\
\hline $\mathrm{Pw}$ & $0 \cdot 42(3)$ & $0 \cdot 28(2)$ & $0.57(3)$ & $0 \cdot 42$ & $0.73(9)$ \\
\hline BS & $0 \cdot 04(2)$ & $0.30(2)$ & $0.72(5)$ & $0 \cdot 35$ & $0.83(8)$ \\
\hline $\mathrm{F}$ & $0 \cdot 00(1)$ & $0.47(2)$ & $0 \cdot 52(3)$ & $0 \cdot 34$ & $0.48(5)$ \\
\hline Pen & $0.00(1)$ & $0 \cdot 21(2)$ & $0.50(4)$ & $0 \cdot 24$ & $0 \cdot 58(6)$ \\
\hline $\mathrm{C}$ & $0 \cdot 28(2)$ & $0.23(2)$ & $0.52(4)$ & $0 \cdot 34$ & $0.71(7)$ \\
\hline G & $0.03(2)$ & $0.39(2)$ & $0.60(4)$ & $0 \cdot 34$ & $0 \cdot 70(6)$ \\
\hline $\mathrm{Bn}$ & $0.49(2)$ & $0 \cdot 35(2)$ & $0 \cdot 64(7)$ & $0 \cdot 49$ & $0.80(11)$ \\
\hline Total site diversity* & $0 \cdot 37(3)$ & $0.49(2)$ & $0.65(7)$ & $0 \cdot 50$ & $0 \cdot 86(17)$ \\
\hline \multicolumn{6}{|l|}{ (b) Sub-site } \\
\hline B1/1 & $0 \cdot 00(1)$ & $0 \cdot 1 \quad(2)$ & $0 \cdot 16(3)$ & $0 \cdot 09$ & $0 \cdot 16(3)$ \\
\hline B1 $/ 2$ & $0.00(1)$ & $0.00(1)$ & $0 \cdot 00(1)$ & $0 \cdot 00$ & $0 \cdot 00(1)$ \\
\hline B $1 / 3$ & $0.00(1)$ & $0.00(1)$ & $0.00(1)$ & 0.00 & $0.00(1)$ \\
\hline B $1 / 4$ & $0.00(1)$ & $0.00(1)$ & $0.00(1)$ & 0.00 & $0.00(1)$ \\
\hline All Bl sub-sites combined & $0 \cdot 00(1)$ & $0.05(2)$ & $0.08(3)$ & $0 \cdot 04$ & $0.08(3)$ \\
\hline B2/1 & $0.45(2)$ & $0.45(2)$ & $0.45(2)$ & 0.45 & $0.46(2)$ \\
\hline B $2 / 2$ & $0.49(2)$ & $0.36(2)$ & $0 \cdot 36(2)$ & $0 \cdot 40$ & $0 \cdot 64(3)$ \\
\hline $\mathrm{B} 2 / 3$ & $0.46(2)$ & $0.31(2)$ & $0.57(3)$ & $0 \cdot 45$ & $0 \cdot 80(6)$ \\
\hline B2/4 & $0 \cdot 46(2)$ & $0 \cdot 34(2)$ & $0 \cdot 43(2)$ & $0 \cdot 40$ & $0 \cdot 70(4)$ \\
\hline All B2 sub-sites combined & $0 \cdot 50(2)$ & $0 \cdot 37(2)$ & $0.47(3)$ & 0.45 & $0 \cdot 70(6)$ \\
\hline $\mathrm{Pw} / 1$ & $0.51(2)$ & $0 \cdot 30(2)$ & $0.61(3)$ & 0.47 & $0 \cdot 80(8)$ \\
\hline $\mathrm{Pw} / 2$ & $0.47(2)$ & $0.26(2)$ & 0.56 & 0.43 & $0.74(7)$ \\
\hline $\mathrm{Pw} / 3$ & $0.43(2)$ & $0 \cdot 28(2)$ & $0 \cdot 50(2)$ & 0.40 & $0 \cdot 69$ (4) \\
\hline $\mathrm{Pw} / 4$ & $0 \cdot 36(2)$ & $0 \cdot 36(2)$ & $0.49(2)$ & $0 \cdot 40$ & $0 \cdot 58(3)$ \\
\hline All Pw sub-sites combined & $0 \cdot 44(2)$ & $0 \cdot 30(2)$ & $0.55(3)$ & 0.43 & $0 \cdot 72(8)$ \\
\hline $\mathrm{G} / 1$ & $0.00(1)$ & $0.48(2)$ & $0.66(5)$ & $0 \cdot 38$ & $0.77(6)$ \\
\hline $\mathrm{G} / 2$ & $0.00(1)$ & $0.43(2)$ & $0.57(4)$ & $0 \cdot 33$ & $0.72(5)$ \\
\hline $\mathrm{G} / 3$ & $0.00(1)$ & $0 \cdot 34(2)$ & $0 \cdot 54(4)$ & $0 \cdot 29$ & $0.67(5)$ \\
\hline $\mathrm{G} / 4$ & $0.00(1)$ & $0 \cdot 32(2)$ & $0.58(4)$ & $0 \cdot 30$ & $0 \cdot 71(5)$ \\
\hline All $\mathrm{G}$ sub-sites combined & $0 \cdot 00(1)$ & $0.41(2)$ & $0 \cdot 66(5)$ & $0 \cdot 36$ & $0.72(6)$ \\
\hline Total sub-site diversity* & $0.45(2)$ & $0.41(2)$ & $0.63(6)$ & $0 \cdot 50$ & $0.82(11)$ \\
\hline
\end{tabular}

* The total site and sub-site diversity describe the genetic diversity and genotypic diversity values for all isolates from all sites and sub-sites respectively, considered as single populations.

diversity for each locus over the number of loci examined and represents the proportion of loci at which two individuals, chosen randomly from the population, can be expected to differ. Milkman (1975), working with $E$. coli, assumed that the effective population size, $N_{\mathrm{e}}$, had exceeded $10^{10}$ for at least $4 N_{\mathrm{e}}$ generations, in which case a genetic diversity of 0.97 would be expected. If we assume that we are dealing with populations of a genetically effective size at least as large as that predicted for $E$. coli, then the mean genetic diversity, $\bar{h}$, for all sites combined $(\bar{h}=0 \cdot 50)$, which is also the value determined by Young (1985), appears relatively low by comparison. The numbers of alleles per locus are comparable with those found by Young (1985) (three, two and seven for G6PD, SOD and BGAL respectively in this study, compared with four, three and seven), which further indicates lower allelic variation in Rhizobium compared 
with $E$. coli (alleles per locus in E. coli, five, six and 19 for G6PD, SOD and BGAL respectively; Selander \& Levin, 1980).

As in the study of Young (1985), strong genetic disequilibrium occurred between loci, in that the number of ETs found was not as might be envisaged from the random coalescence of polymorphism at each locus. This was well demonstrated at the Blackawton site, where the possible number of ETs, based on the number of different alleles at each locus, was 28 , although the observed number was only 11 .

Genetic disequilibrium, combined with the absence of strong allelic variation, means that isolates from diverse sources may be allotted to comparatively few ET classes, a situation which also occurs with E. coli (Caugant et al., 1981; Ochman et al., 1983; Ochman \& Selander, 1984). This indicates that chromosomal variation in the biovar trifolii is limited, either because there is repeated selection for particular genetic lineages or because chromosomal recombination is rare.

\section{Differences in ET genetic variability between sites}

Although genetic variation appeared low in the biovar in general and many ETs recurred at a number of sites (Table 3), a chi-square analysis showed that the frequency of the four most widespread ETs (MFM, MSM, MSS and MSK) varied significantly between sites $\left(\chi^{2}=213 \cdot 22\right.$, 27 degrees of freedom), indicating that populations did have individual genetic identities.

A chi-square analysis of the occurrence of the five most abundant (not widespread) ETs (MFM, MSM, SSQ, SSM and MSS) also indicated a significant difference in the distribution of ETs $\left(\chi^{2}=594 \cdot 94,36\right.$ degrees of freedom).

Populations at different sites differ principally in the presence or absence of a few ETs and their relative proportions, rather than through the occurrence of many radically different ETs.

The amount of genetic variation appeared to be strongly dependent upon the $\mathrm{pH}$ of the soil of origin, which ranged from 4.32 at Tal-y-Bont to 7.52 at Blackawton. The number of ETs per site was positively correlated with $\mathrm{pH}(r=0.799, P<0.001)$, as was the mean genetic diversity, $\bar{h}$ $(r=0.870, P<0.001)$. The number of ETs found at Pwllpeiran and Bronant 2 was, however, greater than would be expected from this correlation. This is probably due to an increase in population size and variability following liming.

Genotypic diversity, $h x$ (Table $4 a$ ) is a measure of the probability of isolating two different ETs from a population at any single time and provides a good representation of genetic variation at the various locations by allowing consideration of ETs rather than loci. Because $h x$ is based on the proportions of ETs, in addition to the number of ETs present, high $h x$ values in a population may be attributed to an even distribution, as well as to the presence of a great variety of ETs. This means that genotypic diversity values may be used profitably to demonstrate differences in qualitative and quantitative variation between sites and in particular to show the dominance of a few ETs at certain sites. Variation expressed in this manner re-inforced the correlation of variation with $\mathrm{pH}(r=0.831 ; P<0.001)$.

Low genotypic diversity and mean genetic diversity values at the two Welsh acidic sites were the result of the occurrence of the particularly dominant ET, MFM (Table 3). This is perhaps explained by the plasmid profile analysis of representative strains. A single plasmid profile (three plasmids of sizes $>550,500$ and $197 \mathrm{~kb}$ ) was indicated for all the MFM isolates at these sites and it might be reasonable to assume that they are the same strain. This strain was not only recurrent at these sites but also appeared in much fewer numbers at Bowstreet and Bronant 2. Although this strain was widespread at relatively adjacent sites, further studies may reveal that its high occurrence in acid soils is due to possession of particular traits providing an ecological advantage in these conditions.

Genetic variation was not dependent upon the number of cells per g of soil at each site, which varied from less than 60 at Tal-y-Bont and Bronant 1 to $2 \times 10^{7}$ at Costessey (Table 1); correlation values for $\bar{h}, h x$ and no. of plasmid profiles against cells $\mathrm{g}^{-1}$ were $0 \cdot 10,0 \cdot 19$ and $0 \cdot 33$, respectively. The number of cells $\mathrm{g}^{-1}$ was also independent of $\mathrm{pH}$, a result contrary to other published reports (Jones et al., 1964; Jones, 1966). 
Table 5. Number of isolates of a particular ET at each sub-site

No. of isolates of ET indicated:

$\begin{array}{lcrrrrrrrrrr}\text { Sub-site } & \text { MFK } & \text { MFM } & \text { MFP } & \text { MSK } & \text { MSM } & \text { MSQ } & \text { MSS } & \text { SSM } & \text { SSQ } & \text { Others } & \text { Totals } \\ \text { B1/1 } & 0 & 33 & 1 & 0 & 0 & 2 & 0 & 0 & 0 & 0 & 36 \\ \text { B1/2 } & 0 & 9 & 0 & 0 & 0 & 0 & 0 & 0 & 0 & 0 & 9 \\ \text { B1/3 } & 0 & 21 & 0 & 0 & 0 & 0 & 0 & 0 & 0 & 0 & 21 \\ \text { B1/4 } & 0 & 7 & 0 & 0 & 0 & 0 & 0 & 0 & 0 & 0 & 0 \\ \text { Totals } & 0 & 70 & 1 & 0 & 0 & 2 & 0 & 0 & 0 & 0 & 73 \\ \text { B2/1 } & 0 & 28 & 0 & 0 & 0 & 0 & 0 & 0 & 51 & 0 & 79 \\ \text { B2/2 } & 0 & 19 & 0 & 0 & 0 & 25 & 0 & 0 & 35 & 0 & 79 \\ \text { B2/3 } & 0 & 16 & 0 & 0 & 9 & 21 & 8 & 7 & 23 & 0 & 84 \\ \text { B2/4 } & 0 & 17 & 0 & 0 & 8 & 26 & 0 & 0 & 30 & 0 & 81 \\ \text { Totals } & 0 & 80 & 0 & 0 & 17 & 72 & 8 & 7 & 139 & 0 & 323 \\ \text { Pw/1 } & 4 & 7 & 0 & 4 & 8 & 8 & 0 & 15 & 27 & 3 & 76 \\ \text { Pw/2 } & 2 & 9 & 0 & 3 & 7 & 6 & 0 & 14 & 31 & 0 & 72 \\ \text { Pw/3 } & 0 & 14 & 0 & 0 & 12 & 0 & 0 & 20 & 38 & 0 & 84 \\ \text { Pw/4 } & 0 & 16 & 0 & 0 & 0 & 0 & 0 & 14 & 39 & 0 & 69 \\ \text { Totals } & 6 & 46 & 0 & 7 & 27 & 14 & 0 & 63 & 135 & 3 & 301 \\ \text { G/1 } & 0 & 12 & 15 & 3 & 27 & 0 & 18 & 0 & 0 & 4 & 79 \\ \text { G/2 } & 0 & 14 & 12 & 4 & 37 & 0 & 17 & 0 & 0 & 0 & 84 \\ \text { G/3 } & 0 & 12 & 7 & 2 & 40 & 0 & 25 & 0 & 0 & 0 & 86 \\ \text { G/4 } & 0 & 11 & 4 & 7 & 32 & 0 & 20 & 0 & 0 & 0 & 74 \\ \text { Totals } & 0 & 49 & 38 & 16 & 136 & 0 & 80 & 0 & 0 & 4 & 323 \\ \text { TOTALS } & 6 & 245 & 39 & 23 & 180 & 88 & 88 & 70 & 274 & 7 & 1020\end{array}$

\section{Differences in ET genetic variability between sub-sites}

The ET data from the sub-sites (Table 5) largely reflected the patterns from the 'parent' site, although there were several deviations in proportions. Greater variation in terms of the number of different ETs, mean genetic diversity, $\bar{h}$, and genotypic diversity, $h x$ (Table $4 b$ ), was again exhibited at sites of higher $\mathrm{pH}$. The frequency counts of any single ET at all sub-sites were transformed by taking their square roots and the data analysed considering the values in groups according to their parent site, using a one-way analysis of variance. $F$ tests, using data for the most frequently occurring ETs over all sub-sites, were significant in all cases except MFM (MSQ, $P<0.05$; SSQ, $P<0.001$; MSM, $P<0.001$; MSP, $P<0.001$; MFM, NS), indicating greater variation between, rather than within sites.

Differences in ETs between sub-sites were based, to a greater extent than at the parent sites, on quantitative and proportional, as opposed to qualitative differences and were significant in the cases of Pwllpeiran and Bronant 2. Chi-square analyses of the most frequently occurring ETs (SSQ, SSM, MFM, MSM and SSQ, MFM, MSQ, MSM respectively) gave significant values $\left(\chi^{2}=52.283\right.$ and 102.72 for 12 degrees of freedom).

Although the sub-site data indicated that distinct populations could exist within sites, restriction of allelic variation was again emphasized $(\bar{h}=0.50$ for all combined sub-sites; Table $4 b$ ).

On the basis that the data from sub-sites of the same major location indicate a relatedness of adjacent populations in terms of their chromosomal status and that similarities, albeit to a lesser extent, also occurred between adjacent major sites (Frongoch and Penglais, Garveston and Costessey; see grid references in Table 1) it is suggested that between-site variation might be influenced by geographical separation.

\section{Plasmid profile variation at different locations}

Plasmid analyses of representative isolates further demonstrated the differential variation existing within the various sites of contrasting ecology. Where possible, 40 isolates per site were classified (19 at Bronant 1). The number of different plasmid profiles varied from three at 

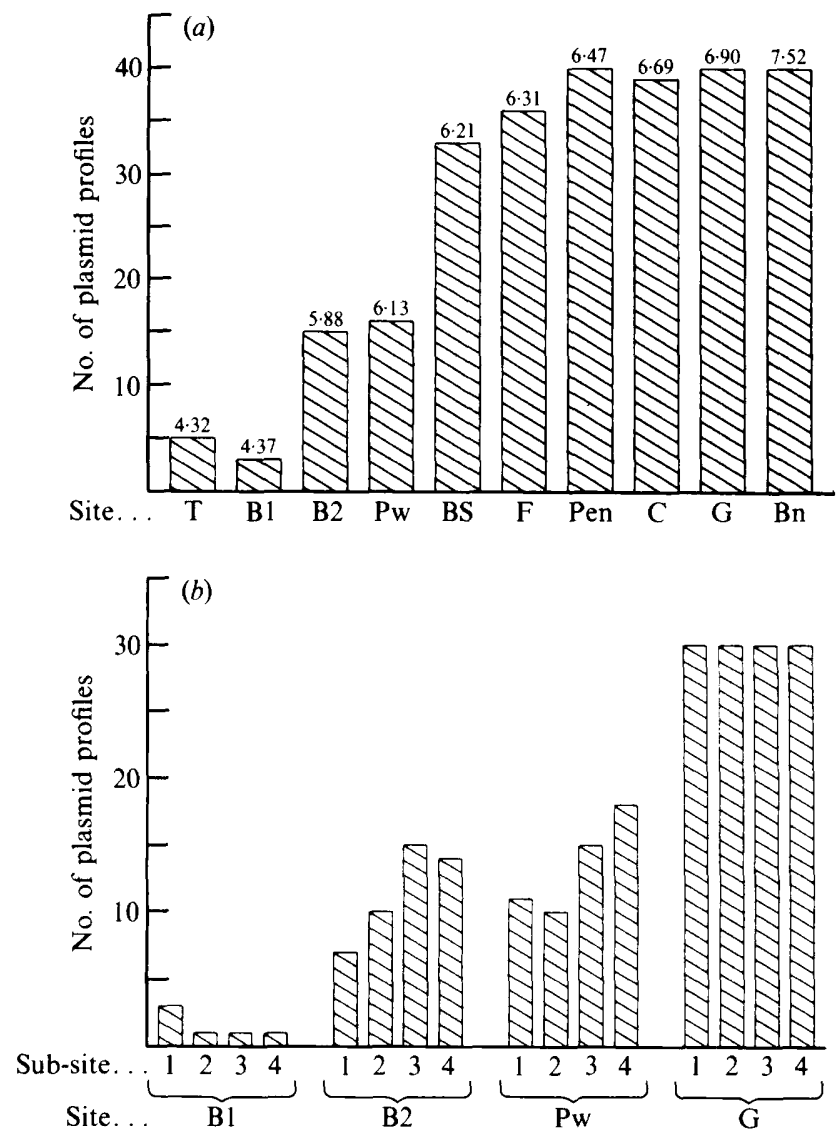

Fig. 1. Number of different plasmid profiles identified at each site $(a)$ and sub-site $(b)$. In $(a)$, the pH value for each site is shown; there was a positive correlation between number of plasmid profiles and $\mathrm{pH}(r=0.90, P=>0 \cdot 001)$.

Bronant 1 to 40 at Penglais, Garveston and Blackawton (Fig. 1a), showing that isolates having the same plasmid profile varied from being in the majority, through many, to few at the acidic, improved and neutral sites, respectively. A strong correlation was again present between genetic diversity (this time in the form of plasmid profile variation) and $\mathrm{pH}(r=0.90, P>0.001)$.

Plasmid profile variability at any particular sub-site appeared to be representative of the parent site (Fig. $1 b$ ). In many cases the profiles found were identical to representatives of the parent site. This was especially obvious at the acidic, Bronant 1 sub-sites, where the MFM strain with a characteristic plasmid profile represented the majority of isolates. At the other extreme, however, the profiles from the Garveston sub-sites were, as in the case of the parent site, greatly variable.

Complementary methods of identification are particularly useful in examining strain polymorphism in populations subject to variation. In this investigation, as in those of other workers (Glynn et al., 1985; Dughri \& Bottomley, 1983a,b, 1984), the use of an additional method has been able to indicate a greater degree of strain variation than suggested by the primary method used alone (for instance at Blackawton, 11 variants were identified by PAGE, whereas 40 were revealed by plasmid profile analysis). Plasmid profile analysis can, therefore, be used to re-evaluate the degree of strain variation at particular sites. An examination of genotypic diversity, $h x$, over the ten sites might indicate that the Bronant 2, Pwllpeiran and Bowstreet sites possess greater isolate variation than Frongoch, Penglais, Costessey and 
Garveston $(0.75,0 \cdot 73,0.83$ versus $0 \cdot 48,0.58,0 \cdot 71,0 \cdot 70$, respectively). However, examination of their plasmid profiles indicates that the converse is true $(15,16$ and 33 versus $36,40,39$ and 40 different profiles, respectively) and that chromosomal variation is more limited at the latter group of sites.

In conclusion, it can be seen that many alleles and ETs are of universal occurrence, implying a certain degree of chromosomal conservation in the biovar trifolii as a whole. Sites had their own identities with respect to the variation present and qualitative ET variation within sites was dependent upon the $\mathrm{pH}$ of the site. There was a high degree of quantitative, rather than qualitative, difference between sites. This was especially so in the case of adjacent sites where the similarity in ET range of populations in close proximity to each other was demonstrated. The potential for variation to occur appeared to be limited in that it was based on the distribution of a few distinct lineages which seem to be subject to strong genetic disequilibrium. The plasmid profile data were more variable, particularly at unstressed sites, and were useful when used in conjunction with enzyme typing in demonstrating a correlation between genetic variation and environmental stress.

During this work S.P.H. was supported by a CASE studentship awarded by the Science and Engineering Research Council and by a grant from the Shell Trust for Higher Education.

\section{REFERENCES}

BERINGER, J. E. (1974). R factor transfer in Rhizobium leguminosarum. Journal of General Microbiology 84, $188-198$.

BrockWELL, J. (1963). Accuracy of a plant infection technique for counting populations of Rhizobium. Applied Microbiology 11, 377-383.

BROMFIELD, E. S. P., INDU, S. B. \& Wolynetz, M. S. (1986). Influence of location, host cultivar and inoculation on the composition of naturalized populations of Rhizobium meliloti in Medicago sativa nodules. Applied and Environmental Microbiology 51, 1077-1084.

Bromfield, E. S. P., Thurman, N. P., Whitwill, S. T. \& Barran, L. R. (1987). Plasmids and symbiotic effectiveness of representative phage types from two indigenous populations of Rhizobium meliloti. Journal of General Microbiology 133, 3457 3466.

Caugant, D. A., Levin, B. R. \& Selander, R. K. (1981). Genetic diversity and temporal variation in the Escherichia coli population of a human host. Genetics 98, 467-490.

Dughri, M. H. \& Bottomley, P. J. (1983a). Complementary methodologies to delineate the composition of Rhizobium trifolii populations in root nodules. Soil Science Society of America Journal 47, 939-945.

Dughri, M. H. \& BotTomley, P. J. (1983b). Effect of acidity on the composition of an indigenous soil population of Rhizobium trifolii found in nodules of Trifolium subterraneum L. Applied and Environmental Microbiology 46, 1207-1213.

DUGHRI, M. H. \& BotTomLeY, P. J. (1984). Soil acidity and the composition of an indigenous population of Rhizobium trifolii in nodules of different cultivars of Trifolium subterraneum L. Soil Biology and Biochemistry 16, 405-411.

ECKHARDT, T. (1978). A rapid method for the identification of plasmid deoxyribonucleic acid in bacteria. Plasmid 1, 584-588.

Glynn, P., Higgins, P., Squartini, A. \& O'Gara, F. (1985). Strain identification in Rhizobium trifolii using DNA restriction analysis and intrinsic antibiotic resistance. FEMS Microbiology Letters 30, 177182.

Harrison, S. P., Young, J. P. W. \& Jones, D. G. (1987). Rhizobium population genetics: effect of clover variety and inoculum dilution on the genetic diversity sampled from natural populations. Plant and Soil 103, 147-150.

Harrison, S. P., Jones, D. G., Schunmann, P. H. D., FORSTER, J. W. \& YOUNG, J. P. W. (1988). Variation in Rhizobium leguminosarum biovar trifolii Sym plasmids and the association with effectiveness of nitrogen fixation. Journal of General Microbiology 134, 2721-2730.

HiRsch, P. R., van Montagu, M., Johnston, A. W. B., BrewiN, N. J. \& Schell, J. (1980). Physical identification of baceriocinogenic, nodulation and other plasmids in stains of Rhizobium leguminosarum. Journal of General Microbiology 120 , 403-412.

JENSEN, H. L. (1942). Nitrogen fixation in leguminous plants. I. General characters of root nodule bacteria isolated from species of Medicago and Trifolium in Australia. Proceedings of the Linnean Society of New South Wales 66, 98-108.

JONES, D. G. (1966). The contribution of white clover to a mixed upland sward. II. Factors affecting density and effectiveness of Rhizobium trifolii. Plant and Soil 24, 250-259.

Jones, D. G., Munro, J. M. M. \& Davies, W. E. (1964). The contribution of white clover to a mixed upland sward. I. The effect of Rhizobium inoculation on the early development of white clover. Plant and Soil 21, 63-69.

MilkmaN, R. (1975). Alloenzyme variation in Escherichia coli of diverse natural populations. In Isoenzymes, vol. IV, pp. 273-285. Edited by C. L. Markert. New York: Academic Press.

NEI, M. (1978). Estimation of average heterozygosity and genetic distance from a small number of individuals. Genetics 89, 583-590. 
NoEl, K. D. \& BRILl, W. J. (1980). Diversity and dynamics of indigenous Rhizobium japonicum populations. Applied and Environmental Microbiology 40, 931-938.

Ochman, H. \& Selander, R. K. (1984). Evidence for clonal population structure in Escherichia coli. Proceedings of the National Academy of Sciences of the United States of America 81, 198-201.

Ochman, H., Whittam, T. S., Caugant, D. A. \& SELANDER, R. K. (1983). Enzyme polymorphism and genetic population structure in Escherichia coli and Shigella. Journal of General Microbiology 129, 27152726.

Selander, R. K. \& Levin, B. R. (1980). Genetic diversity and structure in Escherichia coli populations. Science 210, 545-547.

Selander, R. K., Caugant, D. A., Ochman, H., Musser, J. M., Gilmour, M. N. \& Whittam, T. S. (1986). Methods of multilocus enzyme electrophoresis for bacteria population genetics and systematics. Applied and Environmental Microbiology 51, 873-884.

Thurman, N. P. \& Bromfield, E. S. P. (1988). Effect of variation within and between Medicago and Melilotus species on the composition and dynamics of indigenous populations of Rhizobium meliloti. Soil Biology and Biochemistry 20, 31-38.

VinCENT, J. M. (1970). A Manual for the Practical Study of Root Nodule Bacteria (IBP Handbook no. 15). Oxford \& Edinburgh: Blackwell.

Whittam, T. S., Ochman, H. \& Selander, R. K. (1983). Multilocus genetic structure in natural populations of Escherichia coli. Proceedings of the National Academy of Sciences of the United States of America 80, 1751-1755.

YoUNG, J. P. W. (1985). Rhizobium population genetics: enzyme polymorphism in isolates from peas, clover, beans and lucerne grown at the same site. Journal of General Microbiology 131, 2399-2408.

Young, J. P. W., Demetriou, L. \& Apte, R. G. (1987). Rhizobium population genetics: enzyme polymorphism in Rhizobium leguminosarum from plants and soil in a pea crop. Applied and Environmental Microbiology 53, 397-402. 